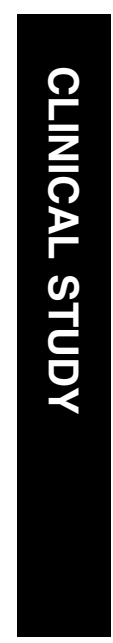

\title{
Can a preoperative bevacizumab injection prevent recurrent postvitrectomy diabetic vitreous haemorrhage?
}

${ }^{1}$ Department of Ophthalmology, St Paul's Eye Unit, Royal Liverpool University Hospital, Liverpool, UK

${ }^{2}$ Department of Ophthalmology, UTMB, Galveston, TX, USA

${ }^{3}$ Department of Ophthalmology, Li Ka Shing Faculty of Medicine, University of Hong Kong, Hong Kong

Correspondence:

MR Romano,

St Paul's Eye Unit,

Royal Liverpool University

Hospital,

Prescot Street,

Liverpool L7 8XP, UK

Tel: + 44796019 2539;

Fax: + 441517065905 .

E-mail: romanomario@

email.it

Received: 16 August 2008 Accepted in revised form: 28 October 2008; published online 28 November 2008

Financial/proprietary interest: None

\begin{abstract}
Aims To evaluate the recurrence rate of vitreous haemorrhage $(\mathrm{VH})$ in patients treated with one intravitreal bevacizumab (IVB) injection $(2.5 \mathrm{mg} / 0.1 \mathrm{ml})$ before planned pars plana vitrectomy for treatment of diabetic nonclearing $\mathrm{VH}$.

Methods Prospective pilot study of 32 eyes of
\end{abstract} 31 consecutive diabetic patients who underwent IVB injection within 1 week before surgery for persistent $\mathrm{VH}$ in the presence of active proliferative diabetic retinopathy. Three masked retinal specialists graded the amount of $\mathrm{VH}$ from grade 0 to grade 3 with slit-lamp biomicroscopy. Main outcome measures were the rate of recurrence of the $\mathrm{VH}$, improvement in visual acuity, incidence of cataract formation, and postoperative complications through a followup of 6 months.

Results The percentage of severe recurrent VH with no fundus details (grade 3 ) was $3 \%$ at 1 week follow-up and 3,6, and $6 \%$ respectively at 1-, 3-, and 6-month follow-up. The mean best-corrected visual acuity (BCVA) improved from $1.6(1 / 60)$ to $0.40(6 / 15) \log$ MAR $(P=0.02)$ in 29 out of 32 eyes (91\%). In all, 12 out of 22 (54\%) phakic eyes developed cataract during the follow-up period, and $10(31 \%)$ of them underwent cataract surgery.

Conclusions Our study suggests that IVB injection few days before planned surgery seems to be efficacious and safe as an adjuvant treatment to prevent rebleeding in eyes undergoing pars plana vitrectomy for treatment of diabetic vitreous haemorrhage. IVB facilitates the surgery and reduces the need for extensive delamination and
MR Romano', SK Gibran², J Marticorena', D Wong ${ }^{1,3}$ and H Heimann ${ }^{1}$ segmentation, decreasing the possibility of significant early active postoperative $\mathrm{VH}$. Eye (2009) 23, 1698-1701; doi:10.1038/eye.2008.354; published online 28 November 2008

Keywords: vitreous haemorrhage; preoperative bevacizumab injection; proliferative diabetic retinopathy

\section{Introduction}

Recurrent non-clearing vitreous haemorrhage $(\mathrm{VH})$ is a significant problem after vitrectomy for proliferative diabetic retinopathy (PDR), and it remains one of the most important causes that lead to further vitreous surgery in these eyes. The reported incidence of recurrent $\mathrm{VH}$ after delamination ranges from 29 to $75 \%{ }^{1}$ during the initial postoperative period, and between 20 and $30 \%$ with longer follow-up. ${ }^{2}$ Spontaneous clearing of postoperative $\mathrm{VH}$ occurs between 5.3 and 16.2 weeks, three times faster in aphakic than in phakic eyes. ${ }^{3}$

The presence of early clear fundus view is necessary to monitor the further course of disease, and it is also important for early visual rehabilitation of these patients. ${ }^{1}$ In addition, there is a higher risk for epiretinal reproliferation in the presence of $\mathrm{VH}$ following pars plana vitrectomy ${ }^{4}(\mathrm{PPV})$.

Studies have shown the correlation between the Vascular endothelial growth factor (VEGF) levels and the severity of PDR, and also a reduction in levels of VEGF after successful laser treatment of PDR. ${ }^{5}$ Inhibition of VEGF may help to halt and possibly treat the ocular neovascularization process. 
Intravitreal bevacizumab (IVB) in humans has been previously described for the treatment of PDR complicated by $\mathrm{VH}$ in non-vitrectomized eyes as adjunct in diabetic delamination. ${ }^{6-8}$ Because of its almost immediate effect on the perfusion of ocular neovascularizations, it might have the potential to decrease the blood flow in neovascular tissues, and thereby decrease the incidence of rebleedings following vitrectomy for PDR. This prospective, interventional, consecutive case series describes our initial experience with IVB in the week before surgery for preventing post-vitrectomy diabetic $\mathrm{VH}$.

\section{Material and methods}

\section{Study design}

Prospective pilot study including 32 eyes of 31 consecutive patients who underwent IVB injection and PPV for persistent VH in the presence of active PDR. The IVB injection was given between 4 and 7 days before the surgery, when avascularity is desired for the possible ease of the surgery.

The patients were recruited at St Paul's Eye Unit, Royal Liverpool University Hospital, between June 2007 and April 2008.

\section{Examination}

Preoperative and postoperative examinations included a detailed past medical history, BCVAusing ETDRS charts and slit-lamp biomicroscopy with particular attention to the grading of $\mathrm{VH}$. The amount of $\mathrm{VH}$ was graded with slit-lamp biomicroscopy by three masked retinal specialists as grade 0 (no VH, clear fundus view/details), grade 1 (mild $\mathrm{VH}$, indentification of fundus details possible, hazy view), grade 2 (moderate $\mathrm{VH}$, impaired view of fundus details, optic nerve just visible), and grade 3 (severe $\mathrm{VH}$, no fundus details, optic nerve head not visible).

The follow-up examinations were scheduled at 1 day, 1 week, and 1-, 3-, and 6-months postoperatively. The BCVA was recorded at each follow-up.

\section{Surgical technique}

Surgery was performed under monitored general anaesthesia or a retrobulbar block. Surgical procedure included a standard three-port PPV using the ACCURUS $^{\circledR}$ vitrectomy machine (Alcon Laboratories Inc., Fort Worth, TX, USA). Delamination, endolaser photocoagulation, and endodiathermy were carefully performed to avoid further rebleeding. During vitrectomy, the vitreous base was thoroughly trimmed, and the retinal periphery was inspected to rule out retinal breaks or any other source of bleeding. Fluid-air exchange was then performed with humidified air and, at the end of the surgical procedure, IVB $(2.5 \mathrm{mg} / 0.1 \mathrm{ml})$ was injected.

The option of the off-label use of IVB during the surgical intervention was discussed with the patients, and written informed consent was obtained from all recruited subjects after having provided a detailed description of the procedure to be used.

\section{Results}

\section{Patients and preoperative findings}

Thirty-one patients (19 male and 12 female) ranging from 34 to 68 years of age (average $46 \pm 13$ ) were treated with IVB injection (between 4 and 7 days before the surgery) and PPV. Twenty-two eyes were phakic and 10 were pseudophakic. Twenty-eight patients had undergone previous panretinal photocoagulation (Table 1). Visual acuity at the time of surgery ranged from $1.6(1 / 60)$ to 1.0 $(6 / 60) \log M A R$, and the fundus was not visible by indirect ophthalmoscopy in 15 out of 32 eyes (47\%).

\section{Functional and anatomical results}

At baseline examination, mean BCVA was $1.6(1 / 60)$ $\pm 1.2 \log$ MAR. At 6-month follow-up, the BCVA had significantly improved in 29 out of 32 eyes (91\%) to 0.4 $(6 / 15) \pm 0.8 \log$ MAR. Preoperative and postoperative values were significantly different $(P=0.02)$. In 3 out of 32 eyes $(9 \%)$, the BCVA was statistically unchanged at 6-month follow-up because of the recurrence of $\mathrm{VH}$ (grade $2-3)(P=0.3)$. The retina was fully attached in all eyes throughout the follow-up period, except for 1 out of 32 eyes $(3 \%)$ that developed a tractional retinal detachment (TRD) in the presence of $\mathrm{VH}$ at 6-month follow-up.

\section{Intraoperative findings}

Preoperative IVB injection proved to be helpful in minimizing the intraoperative bleeding when delaminating the fibrovascular tissue. Less bleeding facilitates surgery and, in theory, makes it safer by reducing the need to raise IOP for haemostasis in these patients, who already have impaired retinovascular perfusion. Very little intraoperative bleeding was noted when cutting fibrovascular tissue that showed the presence of neovessels at ophthalmoscopy before tht injection of bevacizumab. 
Table 1 Demographics of study patients

\begin{tabular}{|c|c|c|c|c|c|c|c|c|}
\hline \multirow[t]{2}{*}{ Patient $\mathrm{n}$} & \multirow[t]{2}{*}{ Eyes } & \multirow[t]{2}{*}{ Age (SD) } & \multirow[t]{2}{*}{$\operatorname{Sex}(M / F)$} & \multirow{2}{*}{$\begin{array}{c}\text { Lens status } \\
\text { (Phakic/pseudophakic) }\end{array}$} & \multirow{2}{*}{$\begin{array}{l}\text { Previous } \\
\text { treatment }\end{array}$} & Type of diabetes & \multirow[t]{2}{*}{ Hypertension } & \multirow[t]{2}{*}{ Oral treatment/insulin } \\
\hline & & & & & & (Type1/Type 2) & & \\
\hline 31 & 32 & $46(13)$ & $19 / 12$ & $22 / 10$ & PRP (28 eyes) & $6 / 25$ & $9(29 \%)$ & $10 / 21$ \\
\hline
\end{tabular}

Table 2 Vitreous haemorrage grading through 6 months follow-up

\begin{tabular}{lcccccc}
\hline \multirow{8}{c}{ Baseline } & \multicolumn{3}{c}{$\begin{array}{c}\text { Vitreous Hemorrhage } \\
\text { n eyes (\%) }\end{array}$} & 3 months & 6 months \\
\cline { 2 - 6 } & 1 day & 1 week & 1 month \\
\hline Grade 0 & 0 & $9(28)$ & $18(56)$ & $23(72)$ & $27(84)$ & $29(91)$ \\
Grade 1 & 0 & $20(62)$ & $12(38)$ & $7(22)$ & $3(9)$ & 0 \\
Grade 2 & $17(53)$ & $2(6)$ & $1(3)$ & $1(3)$ & 0 & $1(3)$ \\
Grade 3 & $15(47)$ & $1(3)$ & $1(3)$ & $1(3)$ & $2(6)$ & $2(6)$
\end{tabular}

Grade 0 (no VH, clear fundus view/details).

Grade 1 (mild VH, fundal details possible/hazy view).

Grade 2 (moderate VH, fundal details possible/optic nerve visible).

Grade 3 (severe VH, no fundal details).

\section{Recurrence of $\mathrm{VH}$}

Postoperatively, no VH could be seen and the fundus was visible with details (within grade 2) in 31 out of 32 eyes $(97 \%)$ at 1-day follow-up. Severe recurrent $\mathrm{VH}$ with no fundus details (grade 3) was found in 3, 3, 6, and $6 \%$ of the eyes at 7 days, 1-, 3-, and 6-month follow-up, respectively (Table 2). All patients with recurrent $\mathrm{VH}$ underwent further surgery, if the haemorrhage persisted at the end of the 6-month follow-up period.

\section{Complications}

Anterior chamber shallowing occurred in 2 out of 32 eyes $(6 \%)$, which were pseudophakic. None of the patients had clinically significant intraocular inflammation in the first postoperative day. Posterior synaechiae were detected in seven $(22 \%)$ patients at 1-month follow-up. In all, 12 out of 22 (54\%) phakic eyes developed cataract during the follow-up period, and 10 (31\%) of them underwent cataract surgery.

\section{Discussion}

It has been postulated that the source of recurrent $\mathrm{VH}$ could be focal, anterior hyaloid proliferation, or fibrovascular ingrowth at sclerotomy sites. ${ }^{9}$ The majority of $\mathrm{VH}$ following vitrectomy occurs in an initial period or immediately postoperatively, ${ }^{1,2}$ and it is, therefore, unlikely to be caused by recurrent proliferation. In our opinion, the main reasons for recurrent $\mathrm{VH}$ are intraoperative surgical manoeuvres, insufficient haemostasis, and persistent retinal neovascularizations.

VEGF is produced in response to hypoxia from capillary loss, and it is a key mediator of angiogenesis and blood retina barrier breakdown in the ischaemic retina. ${ }^{10}$ Thus, inhibition of VEGF activity may play a pivotal role in the prevention of PDR and of bleeding from the new vessels, especially in those located in the preretinal space as in diabetic retinopathy. ${ }^{6}$

In our series, we observe a valid advantage in the use of IVB before the surgical procedures.

The possibility to have a lower rate of recurrence of $\mathrm{VH}$ after IVB treatment involves vessel calibre. The vascular endothelium, and pericytes in particular, are responsible for a number of homoestatic functions, including the maintenance of vascular tone, which is also modulated by vasoconstrictive and vasodilatory factors, such as ET-1 and NO, both influenced by VEGF. ${ }^{11}$ Thus, blockage of VEGF by bevacizumab would be expected to give rise to a transient vasoconstriction, which clinically might mimic vascular regression.

This 'regression' of retinal neovascularization in patients with PDR can occur, but clinical observations indicate that the response to anti-VEGF therapy reverses spontaneously over few days. The real advantage is to plan the PPV during this windows period to reduce the surgical trauma delaminating a fibrovascular tissue that is less perfused.

Yang et $\mathrm{al}^{4}$ found that $10 \% \mathrm{C}_{3} \mathrm{~F}_{8}$ tamponade can be a useful adjunct to vitrectomy for the reduction of early postoperative recurrent $\mathrm{VH}$ ( 1 out of $31,3.2 \%$ ). The same author showed that preoperative bevacizumab injection, such an anti-VEGF, in adjunct to long-acting postoperative tamponade $\left(10 \% \mathrm{C}_{3} \mathrm{~F}_{8}\right)$ increases the clearance of early postoperative $\mathrm{VH}(7.2 \pm 5.6$ days $v \mathrm{~s}$ $15.2 \pm 11.4$ days in no pretreatment group). ${ }^{8}$

In our series, the incidence of VH after PPV does not differ in the initial postoperative period, but in long-term follow-up, the recurrence rate seems to be less than reported in previous literature data. ${ }^{1,2}$ Our hypothesis is that the preoperative bevacizumab injection minimize the intraoperative bleeding during the delamination manoeuvre of the fibrovascular tissue.

One of the thirty-two patients (3\%) developed TRD during the follow-up period. This happened at the 6-month follow-up in a pseudophakic eye with recurrent 
VH from the early follow-up. As overexpression of VEGF has been considered an important factor in the pathogenesis of neovascular process, sudden withdrawl of VEGF may exaggerate the wound healing type respone $^{12}$ in fibrovascular PDR component leading to TRD. In our case, 6 months after IVB injection, the TRD may be likely due to the presence of blood than to antiVEGF therapy.

In conclusion, we believe that IVB injection few days before the surgical approach to PDR facilitates surgery reducing intraoperative bleeding. This reduces the necessity for extensive delamination and segmentation, and therefore lowers the risk of significant early active postoperative $\mathrm{VH}$.

These results have to be weighted considering the limited number of cases and the lack of a control group. Further studies are warranted to determine the efficacy and safety of adjuvant use of IVB injections before delamination/segmentation procedures for PDR in preventing postoperative $\mathrm{VH}$.

\section{References}

1 Novak MA, Rice TA, Michels RG, Auer C. Vitreous hemorrhage after vitrectomy for diabetic retinopathy. Ophthalmology 1984; 91: 1485-1489.

2 Avery RL, Pearlman J, Pieramici DJ, Rabena MD, Castellarin AA, Nasir MA et al. Intravitreal bevacizumab (Avastin) in the treatment of proliferative diabetic retinopathy. Ophthalmology 2006; 113: 1695.e1-1695.e15.

3 Landers MB, Perraki AD. Management of post-vitrectomy persistent vitreous hemorrhage in pseudophakic eyes. Am J Ophthalmol 2003; 136: 989-993.

4 Yang $\mathrm{CM}$, Yeh PT, Yang $\mathrm{CH}$. Intravitreal long-acting gas in the prevention of early postoperative vitreous hemorrhage in diabetic vitrectomy. Ophthalmology 2007; 114: 710-715.

5 Aiello LP, Avery RL, Arrigg PG, Keyt BA, Jampel HD, Shah ST et al. Vascular endothelial growth factor in ocular fluid of patients with diabetic retinopathy and other retinal disorders. N Engl J Med 1994; 331: 1480-1487.

6 Spaide RF, Fisher YL. Intravitreal bevacizumab (Avastin) treatment of proliferative diabetic retinopathy complicated by vitreous hemorrhage. Retina 2006; 26: 275-278.

7 Rizzo S, Genovesi-Ebert F, Di Bartolo E, Vento A, Miniaci S, Williams G. Injection of intravitreal bevacizumab (Avastin) as a preoperative adjunct before vitrectomy surgery in the treatment of severe proliferative diabetic retinopathy (PDR). Graefes Arch Clin Exp Ophthalmol 2008; 246: 837-842.

8 Yang CM, Yeh PT, Yang CH, Chen MS. Bevacizumab pretreatment and long-acting gas infusion on vitreous clear-up after diabetic vitrectomy. Am J Ophthalmol 2008; 146: 211-217.

9 West JF, Gregor ZJ. Fibrovascular ingrowth and recurrent haemorrhage following diabetic vitrectomy. $\mathrm{Br} J$ Ophthalmol 2000; 84: 822-825.

10 Comer GM, Ciulla TA. Pharmacotherapy for diabetic retinopathy. Curr Opin Ophthalmol 2008; 15: 508-518.

11 Warner T. Relationships between the endothelin and nitric oxide pathways. Clin Exp Pharmacol Physiol 1999; 26: 247-252.

12 Kent D, Sheridan C. Choroidal neovascularization: a wound healing perspective. Mol Vis 2003; 9: 747-755. 